\title{
Effect of pattern of preceding inspiration on FEV1 in asthmatic children
}

\author{
L. Sette*, G. Del Col**, A. Comis**, J. Milic-Emili+, A. Rossi++, A.L. Boner*
}

Effect of pattern of preceding inspiration on FEVI in asthmatic children. L. Sette, G. Del Col, A. Comis, J. Milic-Emili, A. Rossi, A.L. Boner. (CERS Journals Ltd 1996.

ABSTRACT: In adults, both peak expiratory flow (PEF) and forced expiratory volume in one second (FEV1) are significantly influenced by the time course of the inspiration preceding the forced expiration. The aim of this study was to evaluate the effects of three different inspiratory manoeuvres on PEF, FEV1, and forced vital capacity (FVC) in asthmatic children.

Twenty five symptomless asthmatic children performed forced expiration preceded by three different inspiratory manoeuvres, which consisted of: a rapid inspiration with a $2 \mathrm{~s}$ end-inspiratory breathhold (Manoeuvre No. 1); a rapid inspiration without an end-inspiratory breathhold (Manoeuvre No. 2); and a slow inspiration lasting about $5 \mathrm{~s}$ with an end-inspiratory breathhold of at least $4 \mathrm{~s}$ (Manoeuvre No. 3). All manoeuvres were performed in a randomly assigned sequence each morning for three consecutive days. In each session, the manoeuvres were repeated three times and the highest value was chosen.

Both FVC and FEV1 obtained with Manoeuvre No. 3 were significantly lower than the corresponding values obtained with Manoeuvre Nos. 1 and 2. The mean (SD) FVC values were $2.76(0.66) \mathrm{L}$ with Manoeuvre No. 1, $2.67(0.58) \mathrm{L}$ with Manoeuvre No. 2 and $2.52(0.52) \mathrm{L}$ with Manoeuvre No. 3. The corresponding values of FEV1 were $2.25(0.53), 2.22(0.53)$ and $2.07(0.44) \mathrm{L}$, respectively. By contrast, the values of PEF, obtained with a portable peak flow meter, were similar with the three different inspiratory manoeuvres.

The results of this study show that in symptomless asthmatic children the preceding inspiratory manoeuvre may influence forced vital capacity and forced expiratory volume in one second. Hence, in order to reduce variability due to interference by physiological factors and so improve reproducibility of pulmonary function tests, the inspiratory manoeuvres must be accurately standardized. Eur Respir J., 1996, 9, 1902-1906.

Forced vital capacity (FVC), forced expiratory volume in one second (FEV1) and peak expiratory flow (PEF) are extensively used to monitor pulmonary function in patients with asthma [1-3]. These measurements are performed using detailed, internationally accepted, guidelines $[4,5]$. Within these guidelines, however, the pattern of the inspiratory manoeuvre preceding the forced expiration has not been standardized. In practice, it involves a maximal inspiration at a speed chosen by the patient, followed by an end-inspiratory breathhold of variable duration. However, it has recently been shown that, both in normal subjects and patients with chronic obstructive pulmonary disease (COPD), FEV 1 and PEF depend markedly on the time course of the inspiration preceding the forced expiration $[6,7]$.

In the present investigation, we studied the effect of three different inspiratory manoeuvres on FVC, FEV1 and PEF in 25 symptomless asthmatic children. The manoeuvres consisted of: 1) a rapid inspiration with a $2 \mathrm{~s}$ end-inspiratory breathhold (Manoeuvre No. 1); 2) a rapid inspiration without an end-inspiratory breathhold (Manoeuvre No. 2); and 3) a slow inspiration lasting about $5 \mathrm{~s}$ with an end-inspiratory breathhold of at least $4 \mathrm{~s}$ (Manoeuvre No. 3 ).
"Pediatric Dept, University of Verona, Verona, Italy. **Istituto Pio XII, Misurina, Italy. +Meakins-Christie Laboratory, McGill University, Montreal, Canada. ${ }^{++}$Respiratory Division, Ospedale Civile Maggiore, Venona, Italy.

Correspondence: L. Sette

Clinica Pediatrica

Policlinico Borgo Roma

37134 Verona

Italy

Keywords: Asthma

children

pattern of inspiration

Received: October 191995

Accepted after revision May 231996

Methods

\section{Patients}

Twenty five children (7 females and 18 males), aged (mean \pm SD) $10 \pm 2$ yrs were recruited for the study. All children suffered from bronchial asthma diagnosed according to American Thoracic Society (ATS) criteria [8], and had a positive skin-prick test response to one or more common allergens (Dermatophagoides farinae or $D$. pteronyssinus, grass pollen and/or parietaria). All were free of respiratory tract infections or symptoms of asthma for at least 4 weeks preceding the study.

The children were resident for at least 3 months at the Istituto Pio XII, Misurina, located in the Italian Alps (1,756 $\mathrm{m}$ above sea level). Because of the regression of symptoms in the pollution and allergen-free environment [9], for at least 1 month preceding the study the children were taking only short-acting beta ${ }_{2}$-adrenergic agonists on an "as needed" basis. Use of short-acting beta ${ }_{2}$-adrenergic agonists was also allowed during the study period. All children were well-trained in the use of the portable peak flow meter and in the performance of forced 
expiratory manoeuvres. Mean $( \pm \mathrm{SD})$ of their lung function data, which correspond to Manoeuvre No. 1 (the manoeuvre usually performed in our lung function laboratory) are presented in table 1.

The study was approved by the Hospital Ethics Committee and informed consent was provided by the childrens parents.

\section{Measurements}

Lung function (FVC and FEV1) was measured in standing position by means of a Vitalograph compact spirometer (Vitalograph, Buckingham, UK) according to a standardized procedure [4]. The predicted values for lung volumes are from Polgar and PROMHADAT [10]. PEF was measured by means of a mini-Wright portable peak flow meter (Airmed, UK). Three new peak flow meters checked for accuracy were used [11]. Each child used the same peak flow meter throughout the study period. In all instances, at least three PEF measurements were obtained in each child. When two values of PEF were within 5\%, the test was considered satisfactory and the highest value was chosen.

\section{Protocol}

The study lasted 5 days. On the morning of the first day, the children were instructed to perform the three types of FVC manoeuvres (Nos. 1-3). On the morning of the second day, bronchial hyperresponsiveness was measured by methacholine challenge, according to the procedure described by HARGREAVE et al. [12], to obtain the provocative concentration causing a $20 \%$ fall in FEV1 relative to baseline (PC20). In addition, instruction of the three different FVC manoeuvres was repeated. The following 3 days were used to obtain the experimental values of FVC, FEV1 and PEF with Manoeuvres Nos. $1-3$. On each of these days, the three FVC manoeuvres were performed in a single morning session, starting at

Table 1. - Pulmonary function data of 25 asthmatic children

\begin{tabular}{|c|c|c|c|}
\hline \multirow{2}{*}{ Parameter } & \multicolumn{3}{|c|}{ Manoeuvre } \\
\hline & No.1 & No.2 & No.3 \\
\hline $\begin{array}{l}\mathrm{FVC} \text { L } \\
\% \text { pred }\end{array}$ & $\begin{array}{l}2.76 \pm 0.66 \\
121 \pm 36\end{array}$ & $2.67 \pm 0.58$ & $2.52 \pm 0.52$ \\
\hline $\begin{array}{l}\mathrm{FEV} 1 \mathrm{~L} \\
\% \text { pred }\end{array}$ & $\begin{array}{l}2.25 \pm 0.53 \\
108 \pm 32\end{array}$ & $2.22 \pm 0.53$ & $2.07 \pm 0.44$ \\
\hline $\begin{array}{c}\mathrm{FEV} 1 / \mathrm{FVC} \% \\
\% \text { pred }\end{array}$ & $\begin{array}{l}84 \pm 9 \\
82 \pm 9\end{array}$ & $83 \pm 9$ & $83 \pm 9$ \\
\hline $\begin{array}{l}\text { PEF 08:00 h } \mathrm{L} \cdot \mathrm{min}^{-1} \\
\% \text { pred }\end{array}$ & $\begin{array}{l}335 \pm 77 \\
114 \pm 30\end{array}$ & $342 \pm 78$ & $346 \pm 79$ \\
\hline PEF 20:00 h $\mathrm{L} \cdot \mathrm{min}^{-1}$ & $349 \pm 79$ & $339 \pm 75$ & $338 \pm 79$ \\
\hline Daily PEF variation \% & $6.3 \pm 7.3$ & $4.6 \pm 3.9$ & $4.5 \pm 3.7$ \\
\hline
\end{tabular}

Values are presented as mean \pm SD. Manoeuvre No. 1: rapid inspiration with $2 \mathrm{~s}$ end-inspiratory breathhold; Manoeuvre No. 2: rapid inspiration without an end-inspiratory breathhold; Manoeuvre No. 3: a slow inspiration lasting about $5 \mathrm{~s}$ with an end-inspiratory breathhold of at least $4 \mathrm{~s}$. FVC: forced vital capacity; FEV1: forced expiratory volume in one second; PEF: peak expiratory flow; $\%$ pred: percentage of predicted value.
08:00 h. PEF was measured twice daily, both in the morning and in an evening session at 20:00 $\mathrm{h}$.

Manoeuvres Nos. 1 and 2 involved a maximal inspiration performed as fast as possible either with a $2 \mathrm{~s}$ breathhold or without it, respectively. Manoeuvre No. 3 consisted of a slow maximal inspiration, which lasted about $5 \mathrm{~s}$, followed by an end-inspiratory breathhold of at least $4 \mathrm{~s}[6,7]$. All manoeuvres were initiated from the resting end-expiratory volume and were performed randomly at a comfortable frequency of one every 2 min. The measurements of FEV1 and PEF were separated by an interval of about $20 \mathrm{~min}$. In order to minimize variations due to longitudinal tension on the trachea [13], the children were requested to maintain the neck at a fixed neutral position during each maximal expiratory manoeuvre. In each session, all manoeuvres were repeated three times, and the highest value was chosen. The values of FVC, FEV1 and PEF obtained in the morning sessions of the three experimental days (Days 3-5) were averaged. The PEF values obtained in the evening sessions of the three experimental days were also averaged.

Children were asked to record the use of beta ${ }_{2}$-adrenergic agents in a diary card and those of them who needed to use short-acting beta $a_{2}$-agonists $\leq 8 \mathrm{~h}$ before lung function assessments were excluded from this study.

\section{Data analysis}

Values are presented as mean \pm SD. Analysis of variance (ANOVA) for repeated measures was used for comparison between the three FVC manoeuvres. If ANOVA showed a significant difference in the groups of data, the Sheffe test was used to assess the difference between two groups of data. Student's paired t-test was used to compare the PEF values obtained by each child in the morning and evening session. The daily PEF variation was computed according to the amplitude-to-mean ratio (\%): daily $\mathrm{PEF}$ variation $=100$ (maximum - minimum) $/$ mean $(\mathrm{PEF})$ [14]. The coefficient of variation $(\mathrm{CoV})$ for FVC, FEV1 and PEF was computed according to the following formula: $\mathrm{CoV}(\%)=100 \mathrm{sD} /$ mean. Linear regression analysis was performed with the least squares method. A p-value equal to or less than 0.05 was considered significant.

\section{Results}

None of the children needed to use beta 2 -adrenergic agonists throughout the study. All children exhibited a significant degree of bronchial hyperresponsiveness reflected by a PC20 methacholine $\leq 8 \mathrm{mg} \cdot \mathrm{mL}^{-1}$ in all instances. One child had a severe bronchial hyperresponsiveness $\left(\mathrm{PC} 20<0.25 \mathrm{mg} \cdot \mathrm{mL}^{-1}\right) ; 19(76 \%)$ had moderate bronchial hyperresponsiveness ( $\mathrm{PC} 200.25-2 \mathrm{mg} \cdot \mathrm{mL}^{-1}$ ); four (16\%) exhibited mild hyperresponsiveness (PC20 2-8 $\left.\mathrm{mg} \cdot \mathrm{mL}^{-1}\right)$; and one child exhibited a borderline responsiveness [12]

The mean values $( \pm \mathrm{SD})$ of FVC, FEV1, FEV1/FVC and PEF obtained with the three different manoeuvres in the 25 asthmatic children are presented in table 1 , whereas mean values $( \pm \mathrm{SD})$ of FVC, FEV1 and FEV1/FVC, with statistical significance, are plotted in figure 1 . The values of FVC, FEV1 and PEF obtained with Manoeuvre 


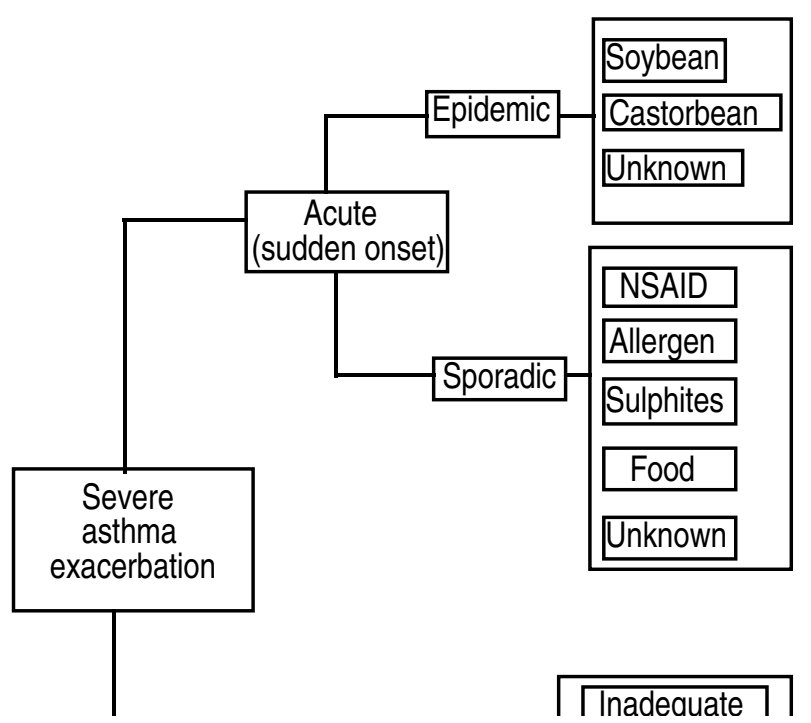

Fig. 1. - a) Forced vital capacity (FVC); b) forced expiratory volume in one second (FEV1); and c) FEV1/FVC ratio, obtained in 25 asthmatic children with the three different inspiratory manoeuvres. Manoeuvre No. 1: rapid inspiration with $2 \mathrm{~s}$ end-inspiratory breathhold; Manoeuvre No. 2: rapid inspiration without an end-inspiratory breathhold; Manoeuvre No. 3: a slow inspiration lasting about $5 \mathrm{~s}$ with an end-inspiratory breathhold of at least $4 \mathrm{~s}$. Ns: nonsignificant.

No. 1 were within or above normal limits [10] in most children (table 1), whilst the values of $\mathrm{FEV} 1 / \mathrm{FVC}$ were less than $80 \%$ in 11 of them. Both FVC and FEV1 obtained with Manoeuvre No. 3 were significantly lower $(\mathrm{p}<0.01)$ lower than the corresponding values with Manoeuvre Nos. 1 and 2, whilst FEV1/FVC did not vary significantly (table 1 and fig. 1). A slight, though significant $(\mathrm{p}<0.05)$, difference in FVC was also found between Manoeuvre No. 1 and No. 2 (table 1 and fig. 1).

With all manoeuvres, the values of PEF were not significantly different between 08:00 $\mathrm{h}$ and 20:00 $\mathrm{h}$ (table 1). Accordingly, the morning and evening values were pooled, and no significant difference in PEF was found between the three manoeuvres. There were no significant differences in daily PEF variation between the three manoeuvres. No significant differences were found among the coefficients of variation of FVC, FEV1, and morning and evening values of PEF obtained with the three manoeuvres.

\section{Discussion}

The results of the present study indicate that in asymptomatic asthmatic children the values of FVC and FEV1 are significantly lower with Manoeuvre No. 3 (slow inspiration with a $4 \mathrm{~s}$ end-inspiratory breathhold) compared to Manoeuvre Nos. 1 and 2. By contrast, the values of PEF obtained with a portable peak flow meter were similar with the three manoeuvres.

The drop in FEV 1 between Manoeuvre No. 2 and No. 3 is consistent with previous results in normal subjects [6] and COPD patients [7], although the magnitude is greater than in the former and smaller than in the latter. In the present study, the difference in FEV 1 between Manoeuvre No. 2 and No. 3, expressed as percentage of the FEV1 obtained with Manoeuvre No. 3, was higher than that obtained in normal subjects $(7.2 \mathrm{vs} 5.7 \%)$, but smaller than in COPD patients $(23 \%)$. The higher values of FEV1 with Manoeuvre No. 2 than Manoeuvre No. 3 in normal subjects and COPD patients have been attributed mainly to: (1) higher elastic lung recoil due to the viscoelastic behaviour of the pulmonary tissues; and (2) changes in bronchomotor tone and balance between airway and parenchymal histeresis $[6,7]$.

The same is probably true in children with asthma, although the latter mechanism may not be entirely comparable. Indeed, whilst in normal subjects and COPD patients maximal lung inflation tends to elicit bronchodilation, the opposite is probably true in asthma [15]. Surprisingly, however, there was no significant difference in FEV1 between Manoeuvre No. 1 and No. 2, though FEV1 with Manoeuvre No. 1 would have been expected to be smaller, in view of the fact that this manoeuvre involved a $2 \mathrm{~s}$ end-inspiratory pause, whilst Manoeuvre No. 2 did not involve any pause, at least normally. However, Manoeuvre No. 2 must, in fact, have involved a finite end-inspiratory pause, even though the asthmatic children had been coached to breathe out immediately after reaching total lung capacity (TLC). Indeed, with the apparatus used in the present study to measure FEV1, the mouthpiece is inserted into the mouth only after inhalation to TLC. This necessarily involves an endinspiratory pause of several hundred milliseconds even with Manoeuvre No. 2 (including reaction time, time to insert the device into the mouth, etc.). Since the viscoelastic time constant of pulmonary tissues amounts to about $1 \mathrm{~s}[16,17]$, as a result of this "spurious" obligatory pause, the differences in FEV1 of Manoeuvre No. 2 compared with Manoeuvres Nos. 1 and 3 should be reduced, as found in the present investigation. In this connection, it should be noted that in the previous studies $[6,7]$ the subjects were connected to the mouthpiece prior to the inhalation to TLC, and the variables characterizing the different FVC manoeuvres were quantified (duration of inspiration to TLC, duration of inspiratory pause, etc.). With the field equipment used in the present study, such quantification was not possible.

In normal subjects and COPD patients, there was no significant difference in FVC between Manoeuvres No. 2 and No. 3. By contrast, in the asthmatic children there was a significant difference in FVC between Manoeuvre No. 2 and No. 3, as well as between Manoeuvre No. 1 
and No. 3. This discrepancy could be due, in part, to the fact that in the present study the measurements of FEV1 and PEF were made without control of lung volume, whilst in the previous studies lung volumes were measured with a body plethysmograph [6, 7]. This implies that in the present investigation the end-inspiratory lung volume prior to the FVC manoeuvre could have varied among the manoeuvres, whereas this was not the case in the previous investigations. However, the present finding of a significant difference in FVC between Manoeuvre No. 2 and No. 3 may also reflect the high inspiratory flow with Manoeuvre No. 2, compared to Manoeuvre No. 3, promoting recruitment of lung units previously sub-tended by closed small airways [18]. Differences in activation of expiratory muscles are unlikely, since they should have influenced the PEF values more than FVC values.

In normal young subjects [6], the residual volume (RV) is determined by the balance between the expiratory muscle strength and the compliance of the chest wall [19], and should be relatively unaffected by any change in elastic recoil pressure of the lung $(P \mathrm{el}, \mathrm{L})$ that might occur due to a specific inspiratory manoeuvre. In contrast, in asthmatic subjects, RV is determined by airway closure and, hence, it may be affected by increased airway stability that should accompany the increase in $P$ el, $\mathrm{L}$ during Manoeuvre No. 3 [20, 21]. It has been shown that patients with emphysema have extensive collateral ventilation, which helps to preserve gas exchange [22]. Such collateral ventilation should also help to preserve the FVC despite enhanced airway closure with Manoeuvre No. 2. In the COPD patients [7], in whom volume during the forced expiration was measured both as expired volume and volume displacement in a plethysmograph, differences in volume due to gas compression were apparent during the FVC manoeuvre, but at the end both volumes were the same. This is in keeping with gas slowly leaving obstructed areas via collateral channels and then leaving the lungs through adjacent unobstructed airways.

In previous studies $[6,7]$ there was a marked difference in PEF between Manoeuvre No. 2 and No. 3. By contrast, no significant difference in PEF was observed in the present study. Since PEF is generally considered to be effort-dependent, this discrepancy may reflect differences in expiratory effort between standing children using the mini-Wright peak flow meter and adults breathing through a pneumotachograph while sitting in a body plethysmograph. In the latter condition, the rate of rise in expiratory electromyographic (EMG) activity was found to be faster in normal subjects during Manoeuvre No. 2 than No. 3, contributing to higher PEF with Manoeuvre No. 2 [6]. In COPD patients, however, no difference in rate of rise of expiratory EMG activity was found between Manoeuvre No. 2 and No. 3 [7]. No such measurements are available for asthmatic children. However, a faster recruitment of the expiratory muscles during Manoeuvre No. 2 should counteract the concomitant increase in elastic recoil of the lung and chest wall, and as a result PEF should remain the same with the two manoeuvres. Part of this discrepancy, however, is probably due to the fact that with the field equipment used to measure PEF there was a "spurious" obligatory pause at TLC, which should have reduced the difference in PEF of Manoeuvre No. 2 with Manoeuvres Nos. 1 and 3.
Clearly, further studies are required to clarify the nature of the present results.

In conclusion, the pattern and time course of the deep inspiratory effort preceding the forced expiration to obtain forced vital capacity can significantly affect the subsequent values of forced expiratory volume in one second in children with asthma in remission. This is in keeping with previous results in normal adults and chronic obstructive pulmonary disease patients. In the present study, at variance with previous investigations, peak expiratory flow was not influenced by the preceding inspiratory effort. This was probably due to the characteristics of the field equipment, which even with Manoeuvre No. 2 involved an obligatory pause of variable duration between the deep inspiration and the forced expiration. These results support the conclusion of previous authors that accurate standardization of the pattern of the deep inspiration preceding forced vital capacity manoeuvres as well as of the end-inspiratory pause is needed to improve the reproducibility of commonly used pulmonary function tests.

\section{References}

1. Williams MH. Expiratory flow rates: their role in asthma therapy. Hosp Pract 1982; 17: 95-110.

2. Lal F, Ferguson AD, Campbell AJM. Forced expiratory time: a simple test for airways obstruction. $\mathrm{Br}$ Med $\mathrm{J}$ 1964; i: $815-817$.

3. Ritchie B. The application of simple methods in the functional assessment of obstructive lung disease and respiratory failure. Med J Aust 1963, 1: 259-262.

4. Quanjer PhH. Tammelin GJ, Cotes JE, Pedersen OF, Peslin R, Yernault J-C. Lung volumes and forced ventilatory flows. Report Working Party. Standardization of Lung Function Tests. European Coal and Steel Community. Eur Respir J 1993; 6 (Suppl. 16): 5-40.

5. American Thoracic Society. Standardization of spirometry. Am Rev Respir Dis 1987; 136: 1285-1298.

6. D'Angelo E, Prandi E, Milic-Emili J. Dependence of maximal flow-volume curves on time-course of preceding inspiration. J Appl Physiol 1993; 75: 1155-1159.

7. D'Angelo E, Prandi E, Milic-Emili J. Dependence of maximal flow-volume curves on time-course of preceding inspiration in patients with chronic obstructive lung disease. Am J Respir Crit Care Med 1994; 150: 15811586.

8. American Thoracic Society. Standards for the diagnosis and care of patients with chronic obstructive pulmonary disease (COPD) and asthma. Am Rev Respir Dis 1987; 136: 225-244.

9. Peroni D, Boner AL, Vallone G, Antolini I, Warner JO. Effective allergen avoidance at high altitude reduces allergen-induced bronchial hyperresponsiveness. Am J Respir Crit Care Med 1994; 149: 1442-1446.

10. Polgar G, Promhadat V. Pulmonary function in children: technique and standards. Philadelphia, W.B. Saunders, 1971.

11. Eichenhorn MS, Beauchamp RK, Harper PA, Ward JC. An assessment of three portable peak flow meters. Chest 1982; 82: 302-309.

12. Hargreave FE, Ryan G, Thomson NC, et al. Bronchial responsiveness to histamine or methacholine in asthma: measurement and clinical significance. J Allergy Clin Immunol 1981; 68: 347-358.

13. Melissinos GC, Mead J. Maximum expiratory flow changes induced by longitudinal tension on the trachea in normal 
subjects. J Appl Physiol: Respirat Environ Exercise Physiol 1977; 43: 537-544.

14. Quackenboss JJ, Lebowitz MD, Kryzanowsky M. The normal range of diurnal changes in peak expiratory flow rates: relationship to symptoms and respiratory disease. Am Rev Respir Dis 1991; 143: 323-330.

15. Orehek J, Nicoli MM, Delpierre S, Beauprè A. Influence of a previous deep inspiration on the spirometric measurement of provoked bronchoconstriction in asthma. Am Rev Respir Dis 1981; 123: 269-272.

16. Guèrin C, Coussa ML, Eissa NT, et al. Lung and chest wall mechanics in mechanically-ventilated COPD patients. J Appl Physiol 1993; 74: 1570-1580.

17. D'Angelo E, Robatto FM, Calderini E, et al. Pulmonary and chest wall mechanics in anesthetized paralyzed humans. J Appl Physiol 1991; 70: 2602-2610.
18. Robertson PC, Anthonisen NR, Ross D. Effect on inspiratory flow rate on regional distribution of inspired gas. J Appl Physiol 1969; 26: 17-23.

19. Leech JA, Ghezo H, Stevens D, Becklake M. Respiratory pressures and function in young adults. Am Rev Respir Dis 1983; 128: 17-23.

20. Zapletal A, Desmond KJ, Demizio DL, Coates AL. Lung recoil and the determination of airflow limitation in cystic fibrosis and asthma. Pediatr Pulmonol 1993; 15: 1318.

21. Anthinisen NR. Closing volume. In: West JB, ed. Regional Differences in the Lung. New York, Academic Press 1977; pp. 451-482.

22. Morrel NW, Wignal BK, Biggs T, Seed W. Collateral ventilation and gas exchange in emphysema. Am J Respir Crit Care Med 1994; 150: 635-641. 